\title{
Capsule Commentary on Winkelman et al., Health Insurance Trends and Access to Behavioral Healthcare Among Justice-Involved Individuals-United States, 2008-2014
}

\author{
Matthew Tobey, MD MPH \\ Division of General Internal Medicine, Massachusetts General Hospital, Boston, MA, USA.
}

J Gen Intern Med 31(12): 1510

DOI: $10.1007 / \mathrm{s} 11606-016-3864-2$

(c) Society of General Internal Medicine 2016

$\mathrm{T}$ his analysis by Winkelman et al. ${ }^{1}$ describes self-reported insurance status and utilization of certain care services among a sample of United States community-dwelling adults who reported recent involvement in the criminal justice system. The results, which offer insight into the effects of the Affordable Care Act (ACA), suggest important gains in insurance status from both the 2010 dependent coverage mandate and the 2014 reforms that included Medicaid expansion, subsidized insurance plans, marketplace implementation, and the individual coverage mandate.

The ACA's dependent coverage mandate of 2010 led 2.5 million more young adults to obtain insurance coverage. ${ }^{2}$ In this study, outsized gains were noted in justice-involved individuals in the eligible age range (19-25). This is an important subpopulation; in this analysis, $31 \%$ of justice-involved individuals were $19-25$, as are roughly $15 \%$ of state prisoners. ${ }^{3}$ Insurance gains may have been reaped mostly by individuals with better socioeconomic profiles, given that the expansion applied only to dependents whose parents are privately insured.

The ACA reforms of 2014 reached a near-full effect on insurance rates in $2015 .{ }^{4}$ Thus the study's finding that the ACA increased coverage - relying on surveys administered in 2014 -is unlikely to represent the full effect of the reforms. Despite improving, the rates of the uninsured among justiceinvolved individuals remained high, twice that of the general population, suggesting that barriers remain. Also, the study left unanswered the question of whether differential effects exist between states that did and did not expand Medicaid.

The study demonstrated that uptake of some mental health and substance use disorder treatment was higher in insured groups over 2008-2014. One implication could be that the ACA's effects on insurance coverage will generate increased uptake of services.

Together, these findings offer important insight into how a uniquely vulnerable group has fared under the ACA. Strategies by which communities and health systems may best leverage ACA reforms for the justice-involved population were recently reviewed. ${ }^{5}$ The complexities of achieving health equity for these populations are likely to require targeted and comprehensive interventions. Nevertheless, the ACA appears to have loosened the shackles of the uninsured - communities and providers may take the next steps.

Corresponding Author: Matthew Tobey, MD MPH; Division of General Internal MedicineMassachusetts General Hospital, Boston, MA, USA (e-mail: mltobey@partners.org).

\section{Compliance with Ethical Standards:}

Conflict of Interest: The author declares that he does not have a conflict of interest.

\section{REFERENCES}

1. Winkelman TNA, Kieffer EC, Goold SD, et al. Health insurance trends and access to behavioral healthcare among justice-involved individuals-United States, 2008-2014. J Gen Intern Med. doi:10.1007/s11606-016-3845-5

2. Sommers BD, Buchmueller T, Decker S, Carey C. The Affordable Care Act has led to significant gains in health insurance and access to care for young adults. Health Aff. 2013;32(1):165-174. doi:10.1377/hlthaff.2012.0552.

3. Carson EA, Sabol WJ. Aging of the State prison population, 1993-2013. US Department of Justice, Bureau of Justice Statistics. 2016. http://www.bjs. gov/index.cfm?ty=pbdetail\&iid=5602. Accessed 8/23/16.

4. The Kaiser Commission on Medicaid and the Uninsured. Key facts about the uninsured population. 2015. The Henry J Kaiser Family Foundation. http://kff.org/uninsured/fact-sheet/key-facts-about-the-uninsured-population/. Accessed 8/23/16.

5. Heiss C, Somers SA, Larson M. Coordinating access to services for justiceinvolved populations. Milbrank Memorial Fund Issue Brief. 2016. http:// www.milbank.org/publications/milbank-issue-briefs/545-coordinating-access-to-services-for-justice-involved-populations. Accessed 8/23/16.

Published online September 13, 2016 